\title{
Upper gastro-intestinal bleeding in Erbil Governorate
}

\author{
Nooraddin I. Alla Qoli \\ Department of Surgery Rizgary Teaching Hospital Erbil-Iraq
}

(Ann. Coll. Med. Mosul 2008; 34(2): 135-140).

Received: $23^{\text {rd }}$ Sept 2007; Accepted: 11 ${ }^{\text {th }}$ June 2008.

\begin{abstract}
Objectives: To define the aetiology, management, and outcome of upper gastro-intestinal bleeding, and to assess the role of endoscopy in the management. Also to assess the factors to improve the management of this problem in this region.
\end{abstract}

Patients \& methods: A prospective study of 102 patients admitted to the main hospitals under the care of the author (1999-2006). Patients were assessed, resuscitated, and investigated by the standard methods. All were endoscoped by the author (OGD).

Fifty patients were treated surgically, by laparotomy and according to the findings; mainly under running suturing of bleeding duodenal ulcers. Analysis of the causes, type and source of bleeding, indications of surgery, and the role of endoscopy was done.

Results: Total number of patients was 102, ninety males (88.2\%), and 12 females (11.8\%). Age range was (8-68years), with peak incidence at the fourth decade. All patients were admitted to hospital, and received blood (2-18 units). Melena was found in 22 patients (2 1.5\%). History of aspirin and NSAID ingestion was found in 18 patients (17.6\%). All patients were endoscoped during day working hours. Causes of bleeding were: Chronic d.u. in 60 patients $(58.8 \%)$ oesophageal varices in 15 patients (14.7\%), and no source of bleeding could be detected in 7 patients (6.8\%). Fifty patients needed surgery (laparotomy); active bleeding vessel was the main pathology, present in 20 cases (40\%). Fifty two patients were managed successfully on conservative treatment.

Conclusion: The most common cause of upper g.i.t. bleeding in Erbil is bleeding duodenal ulcer, followed by oesophageal varices. Gastroscopy proved to be a reliable and accurate method for diagnosis and treatment. Lack of facilities for therapeutic endoscopy and intensive care, led to a high percentage of surgical treatment in about $50 \%$ of patients. Improvement of health infrastructure is essential to achieve a better care for our patients.

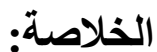

$$
\begin{aligned}
& \text { تم در اسة (r • (1) حالة من النزف الحاد من الجزء العلوي في الجهاز الهضمي ـ أسبابه وعلاجه و نتائجه في ثناث }
\end{aligned}
$$

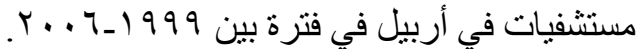

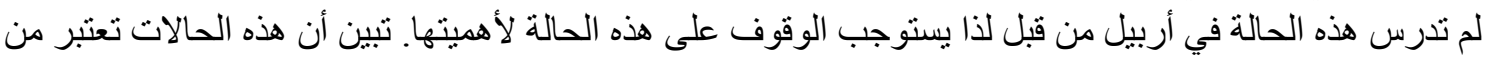

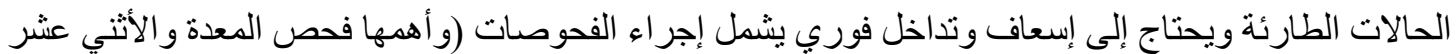

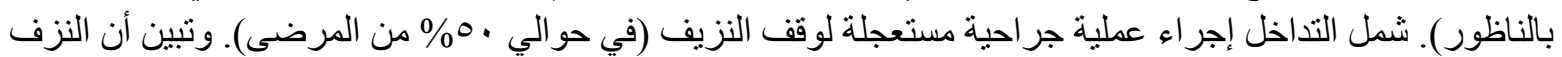

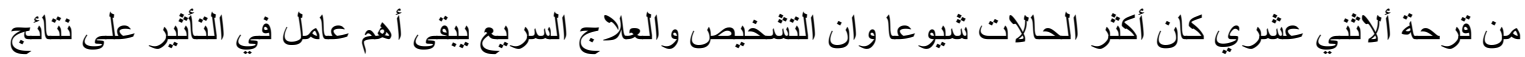

$$
\begin{aligned}
& \text { العلاج. } \\
& \text { أن عدم توفر الأجهزة الناظورية وملحقاتها الخاصة بالتداخل العلاجي (ومنها إيقاف النزيف) أدى إلى ارتفاع عدد العمليات } \\
& \text { الجر احية للمرضى. ونوصي بتوفير ها لرفع مستوى المعالجة المقدمة لمرضانا. }
\end{aligned}
$$


$\mathrm{U}$ pper gastro-intestinal bleeding (GIB) is defined as blood loss originating from near the Treitz' ligament and proximal, usually diagnosed by haematemesis, melaena or both, or sometime by the presence of blood in nasogastric tube.

Acute upper GIB is a common medicosurgical emergency that carries a hospital mortality of $10-14 \%$ and that has not changed over the new century ${ }^{(1)}$. It accounts for 300,000 hospitalizations annually in the U.K. ${ }^{(1)}$. Acute massive GIB has an incidence of 40-150 episodes per 100,000 people annually ${ }^{(2)}$.

The epidemiology of upper GIB differs and varies in different geographic regions, depending on socioeconomic status, age of the patients, history of complication of duodenal ulcer ${ }^{(2)}$, alcohol consumption, smoking habit and the abuse of NSAIDs has major role ${ }^{(3)}$, though it has changed during the last 15 years probably due to common use of proton pump inhibitors. Risk stratification is possible from information available at the time of initial presentation which may be severe bleeding with haematemesis, haematochezia, hypotension, gradual bleeding with melaena or as occult blood in the stool ${ }^{(4)}$.

In our region there are no figures of the incidence, size and management of the problem; to our knowledge, there are no published studies dealing with these aspects of the problem.

We conducted this prospective study, in an effort to evaluate the problem of upper GIB in our region, and to assess the size of the problem in Erbil Governorate, to study the problem in terms of: presentation, causes, diagnosis, and treatment. Also to establish a base line for future planning to improve the management of this serious illness.

\section{Patients and Methods:}

This is a prospective study done in Erbil Governorate from March 1999-May 2006. All patients (102) were admitted to the Emergency units in three main hospitals in Erbil, under the care of the author. There were no exclusion criteria. Detailed history and physical examination were done, then resuscitation according to the expected amount, rate and duration of blood loss.
The initial steps in the evaluation were based on the perceived rate of bleeding and degree of haemodynamic stability. The airway, breathing, and circulation were assessed regularly, blood was drawn for complete blood count, for typing and cross matching. A largebore i.v. line was placed to ensure immediate i.v. access should the patients subsequently become unstable. Urinary catheter was inserted and urine output monitored. Insertion of nasogastric tube and aspiration was helpful in localization of bleeding and demonstration of rebleeding ${ }^{(5,6)}$.

All patients were endoscoped by the author. Patients were put in the left lateral position; mild sedation (diazepam 5-15 mg. i.v.) was given. Olympus GIF, PIO, and XP2O Gastroscopes were used. No patient was treated endoscopically, for lack of therapeutic facilities. After OGD the information obtained was used to continue treatment conservatively or operatively. When a patient remained unstable and continued to bleed despite supportive treatment, he was explored, and bleeding site verified. At operation the duodenum was mobilized and anterior longitudinal duodenotomy was performed over the site of suspicious area and when the bleeder was found, it was ligated with synthetic absorbable sutures \{Polyglycolic acid (Dexon) and polygalactin (Vicryl)\}. When there was only ooze it was under run.

The main indications for exploration were:

1- Patient remains unstable and continues to bleed.

2- Severe tachycardia and hypotension despite supportive treatment and adequate blood transfusion.

3- Fresh jet of arterial bleeding at the ulcer (on OGD).

Fifty patients were explored out of 102 (50\%). The rest, 52 patients were treated conservatively according to the etiology.

\section{Results:}

A total of (102) cases of upper G.I.B were admitted to three major hospitals in Erbil governorate between (March 1999-May 2006) under the author's care. There were 90 $(88.2 \%)$ males and $12(11.8 \%)$ females, the age ranged between (10-68) year. 
It is clear that those patients in $4^{\text {th }}$. decade of life, both males and females constituted the largest cohort (37.7\% and 50\% respectively).

The results were summarized as following:

1. All patients were admitted to hospital, and received blood (from 2 to 18 units).

2. All female patients (12), and (60) male patients were hypotensive on admission (B.P ranged from undetectable to 90/50).

3. Melaena on admission was found in only (22) patients; (18 males and 4 females).

4. History of aspirin and NSAIDs therapy was found in (18) patients (17.6\%) (10 males and 8 females).

5. First attack in 80 male patients and in (10) females (total 88.2\%).

6. Second attack in (9 males and 2 females) $(10.7 \%)$. Third attack in only one male patient $(0.9 \%)$.

7. Smoking history was found in (72) males (70.5\%) and none in females.

8. There was no significant difference in the number of patients from rural or urban areas (48 rural and 54 urban).

9. Endoscopic findings (Table 2).
Chronic duodenal ulcer bleeding constituted ( 5 $8.8 \%$ ) of the cases. Conservative management was successful in (52) cases, while (50) patients were explored; the main findings were:

- Active bleeding (spurting b.v.): 20 cases (40\%); 19 posterior duodenal ulcers; one benign gastric ulcer at the incisura

- Ooze of varying degrees, moderate severe in 20 cases (40\%): 14 posterior d.u., three inferior, one superior, one anterior antral gastric ulcer, and one case of severe antral erosive gastritis.

- Clot in three cases (6\%): two posterior post bulbar ulcers. The third was in a patient with two kissing ulcers in the bulb, but only the posterior one was bleeding.

- No source could be detected both endoscopically and at exploration in seven cases (14\%), in spite of examining the second part of the duodenum at endoscopy, and full exploration surgically.

Table (1): The number, gender, and the age group of 102 patients with upper (GIB).

\begin{tabular}{|c|c|c||}
\hline Age & Males & Females \\
\hline \hline $10-19$ & 2 & 0 \\
\hline $20-29$ & 5 & 6 \\
\hline $30-39$ & 34 & 2 \\
\hline $40-49$ & 26 & 1 \\
\hline $50-59$ & 22 & 1 \\
\hline $60-69$ & 1 & 12 \\
\hline Total & 90 & 2 \\
\hline
\end{tabular}

The (2): Endoscopic finding in 102 patients with upper G.I. bleeding

\begin{tabular}{|c|c|c|c|c|}
\hline Diagnosis & No. of patients & Active bleeding & Clot & ooze \\
\hline Ch.D.U. & $60(58.8 \%)$ & 20 & $\overline{30}$ & 10 \\
\hline Gastric ulcer & $4(3.9 \%)$ & 1 & 3 & $\mathbf{0}$ \\
\hline Oes. varices & $15(14.7 \%)$ & $\mathbf{0}$ & $\mathbf{0}$ & 15 \\
\hline Oesophagitis & $2(1.9)$ & $\mathbf{0}$ & 1 & 1 \\
\hline Ca.of oesophagus & $4(3.9 \%)$ & $\mathbf{0}$ & 3 & 1 \\
\hline Gastritis & $4(3.9 \%)$ & $\mathbf{0}$ & 3 & 1 \\
\hline Ca. of stomach & $3(2.9 \%)$ & $\mathbf{0}$ & 3 & $\mathbf{0}$ \\
\hline Stomal bleeding & $1(0.9 \%)$ & $\mathbf{0}$ & 1 & $\mathbf{0}$ \\
\hline No source & $7(6.8 \%)$ & $\mathbf{0}$ & $\mathbf{0}$ & $\mathbf{0}$ \\
\hline Duodenal erosion & $2(1.9 \%)$ & $\mathbf{0}$ & $\mathbf{0}$ & 1 \\
\hline
\end{tabular}




\section{Discussion:}

In this series, 52 patients (50.9\%) stopped bleeding on conservative management. Compared to a study by Palmer (2004) ${ }^{(7)}$, their figure was $80 \%$. The big difference is obvious: it seems that we have to operate on our patients either earlier, or because of lack of diagnostic, supportive, and facilities for strict monitoring of our patients. We obviously lack some of the needed facilities for that; mainly lack of 24 hours endoscopy service, and proper ICU.

The different causes of bleeding seem to be the same as other studies in the west, but with different percentages. Mallory-Weiss syndrome was not diagnosed in this series, while it was responsible for $3.9 \%$ of bleeding in a study done by Mase ${ }^{(8)}$; this is mostly due to very low alcohol consumption in this region. Dieulafoy's lesion was present in $0.9 \%$ in this series, while it was $5 \%$ in another series ${ }^{(8)}$.

Oesophageal varices was the second common cause of bleeding (14.7\%). In our region it is a much less frequent cause, compared to a study done in Kuwait (27.7\%), due to Egyptian expatriates ${ }^{(9)}$.

Endoscopy is the most accurate and practical method for diagnosing the source of upper GIB. Even in the absence of specific endoscopic therapy as in our region, the prognostic information obtained from the procedure can significantly reduce the use of health resources ${ }^{(10)}$. Endoscopy helped in this way in 20 patients with d.u. (spurting bleeder found, unlikely to respond to conservative treatment). If it wasn't for endoscopy, there would have been more delay, with subsequent morbidity and mortality for the patient, and the use of more resources unnecessarily. On the other hand, endoscopy also helped in the decision to continue conservative treatment and avoided unnecessary surgery with its morbidity and cost..

Fifty two of our patients (50.9\%) were managed conservatively with excellent prognosis, bleeding stopped and circulatory restorative therapy all that was required, compared to $80 \%$ in a study done by Palmer $(2004)^{(7)}$. This is due to the higher percentage of surgery in our patients, and the lack of facilities for ICU and strict monitoring and follow up.

Although optimal resuscitation before endoscopy and proper pharmacological intervention after endoscopy seems to be as crucial to the management of patients with upper GIB as meticulous haemostatic techniques during the procedure, ${ }^{(11)}$ we were able to manage our patients safely. But the lack of endoscopic therapeutic facilities led to a high percentage of surgical interference (about $50 \%$ of our patients).

In our region endoscopy is available only during day working hours, and that had its drawbacks in the diagnosis, follow-up, and planning of the management, since 24 hour endoscopy service is important to achieve diagnosis and plan the management ${ }^{(12)}$.

Endoscopy provides important informations; of these, the poor prognostic signs like active spurting bleeding (unlikely to respond to conservative treatment), and no bleeding lesion (source of bleeding), with subsequent difficult decision and planning of management. Prognosis largely depends on the Rockall risk score which can help and support the clinical decision ${ }^{(13)}$.

In our series real source bleeder was found (at both endoscopy and laparotomy), in 20 cases $(40 \%)$, ooze in 20 patients $(40 \%)$, and clot in 3 cases $(6 \%)$, while no source was found in 7 patients (14\%). Compared to a similar series ${ }^{(14)}$, the figures were: $11.8 \%$, $15.4 \%, 12.5 \%$, and $34.3 \%$ respectively. It is obvious that we probably operated on patients (bleeding and oozing ulcers and erosions) that were mostly treated endoscopically in the compared series.

We have found that the most important cause of major life threatening acute upper GIB is peptic ulcer which is almost the same finding of others $(30 \%, 50 \%)^{(12,15,16)}$.

While history of aspirin and NSAIDs consumption was found in $17.6 \%$ of our patients, in another study it was found only in $2.8 \%{ }^{(17)}$. Probably our patients consume more aspirin and NSAIDs. The pooled relative risk of bleeding after NSAIDs was $3.8 \%{ }^{(18)}$, while 
with aspirin it was $1.9 \%{ }^{(19)}$. Recent NSAIDs users were found to bleed from ulcer mostly duodenal, and to have H. pylori infection more frequently than upper GIB with negative history ${ }^{(20)}$. We have not studied $H$. pylori infection in our patients, but we are starting to do that to improve our treatment of patients with upper GIB.

No source of bleeding was found in 7 patients (14\%), both at endoscopy and surgery, while in other series it was $24 \%{ }^{(21,22)}$. Recently different treatment modalities were studied like injection of clot induced factor, a combination of injection and thermal therapies, and the use of mechanical devices such as clips, ligature. All are promising, however there are at the present no data to suggest that any one of these is superior when looking at the overall group of patients with bleeding ${ }^{(16)}$. Neither the above-mentioned tools nor tagged red cell scan, angio, and video capsule endoscopy are available. Although recurrence after endoscopic therapy occurs in $24 \%$ of high risk patients ${ }^{(23)}$, and adding proton pump inhibitor to endoscopic treatment reduces the rate to $10 \%{ }^{(13)}$, or $50 \%{ }^{(24)}$, we hope to improve the standard of management of our patients by acquiring the needed instruments and expertise in this important field.

\section{Conclusions:}

Most patients were males (88\%). Duodenal ulcer and oesophageal varices are the most common causes of upper $\mathrm{GI}$ bleeding in Erbil Governorate.

Upper g.i.t. endoscopy proved to be reliable and accurate, both in the diagnosis of the source of bleeding, and the decision for surgical (operative) treatment. About $50 \%$ of patients were operated on to stop the bleeding; which is a high percentage, mostly due to: unavailability of 24 hour endoscopy facilities, and lack of endoscopic therapeutic equipment.

The findings from this study may have implications on health care situation in this Governorate, if improved health care services delivery and health outcomes are to be achieved.
We recommend improvement of health infrastructure, like the equipments for different methods of therapeutic endoscopy. and the needed facilities to establish proper intensive care units.

\section{Acknowledgements:}

My thanks to: my patients, and to medical and nursing staff at the three main hospitals in Erbil. Special thanks to Nian and to Shadan for typing the manuscript.

\section{References:}

1. Rockall 5, Logon RF, Devlin HB. Incidence of and mortality from acute upper G.I bleeding in United Kingdom. Steering committees of the national audit of acute upper $\mathrm{Gl}$ bleeding. BMJ.1995;31:222-6

2. Lindo L, Dimmitt M, Steven G. Diagnosis of gastrointestinal bleeding in adult. American Family Physician. April 2005

3. Perez 5, Rodriguez G. Individual non steroidal anti inflammatory drugs, and other risk factors for upper G.I bleeding and perforation. Epidemiology. 1997;8(1): 18

4. Douglas A, Anderson C. Early indicators of prognosis in upper gastrointestiiial haemorrhage. The American journal of gastroenterology. 1998;93:336.

5. Ghosh S. Watt D. Management of gastrointestinal hemorrhage. Postgraduate Medical Journal .2002;78:414

6. Hawke G, Cole A. Drug treatment in Upper GI bleeding, value of endoscopic findings as surrogate end points. GUT. 200 1;49:372 - 79

7. K Palmer. Management of haematemesis and melena.

Postgraduate Medical Journal. 2004; 80:399-404

8. Mase J, Thayer D, Walter E. Historical perspective on upper endoscopy at Rhode, Medicine and Health Rhode Island. Nov 2005

9. Abdulkareen Y, Hassan F. Acute upper G.I bleeding in Kuwait. Kuwait Medical Journal. 2001;33(2): 144-7. 
10.Barkun A. Consensus recommendations for managing patients with non vericeal upper gastrointestinal bleeding, Ann intern med. 2003;139:843-57.

11. Wassef W. Upper gastrointestinal bleeding. Gastroenterology. 2004;20(6): 538-2.Agbakwuru F. Pattern and validity of clinical diseases of upper gastrointestinal disease in South-West Nigeria. African health science. 2006;6(2):98-103

12. Ricchard S. Endoscopy for non vericeal upper GI bleeding. American family Physician. August 2005.

13.Sultan M, Nabi G. A comparison of omeprozole and placebo for bleeding peptic ulcer. The New England Journal Medicine. 1 997;336: 15

14.Eric S. Upper gastrointestinal bleeding. ACS Surgery [serial online] 2008[cited 2008 March 25]; [9 screens]. Available from: URL :http ://www. acssurgery. com/acsonline

15. Kasem A. Management of acute upper GIB in a district hospital. Journal of laparoendoscopic and advanced surgical techniques. Aug 2006;16(4):355-61.

16. Capet C, Czernichow P. Upper gastrointestinal bleeding in patients treated by low dose Aspirin. Gastroenterol Clin Biol. 2001;25(3): 2338.

17. Hernandez-Diaz 5, Alberto L. Association between non steroidal anti- inflammatory
Drugs and upper G.I bleeding. Arch intern med. 2000;160:2093-99.

18. Francis K, Chon E, Sydney C, Bing Ye S. Preventing recurrence of UGB in patients with Helicobacter pylon infection who are taking low dose Aspirin or Naproxen .The New England Journal of Medicine. 2000;34(13):967-73

19. Mitromaras M, Mountakalakis T. Acute upper $\mathrm{Gl}$ bleeding, comparison between recent users and non users of NSAID .Endoscopy 2003;35:327-32

20.Adamopoulus AB, Baibas D. Differentiation between patients with acute upper gastrointestinal bleeding who need early urgent upper G.I endoscopy and those who do not. Eur J Gastroenterol Hepatol.2003;15(4):381-7.

21. Kethy $D$, Reinentse $R$. Low utility of endoscopy for suspected upper gastrointestinal bleeding occurring in hospitalized patients, South Med J. 2005;90 (2):170-5

22. Hawkey GM, McIntyre C. Drug treatment in upper gastroentional bleeding. Med line gut. 2001;49(3):372-9.

23. Munkel L, French L. Treatment of bleeding peptic ulcer with omeprozole. Journal of family practice. July 1997. 